\title{
Transcriptome analysis of various flower and silique development stages indicates a set of class III peroxidase genes potentially involved in pod shattering in Arabidopsis thaliana
}

\author{
Claudia Cosio $^{1 *}$, Christophe Dunand ${ }^{2}$
}

\begin{abstract}
Background: Plant class III peroxidases exist as a large multigenic family involved in numerous functions suggesting a functional specialization of each gene. However, few genes have been linked with a specific function. Consequently total peroxidase activity is still used in numerous studies although its relevance is questionable. Transcriptome analysis seems to be a promising tool to overcome the difficulties associated with the study of this family. Nevertheless available microarrays are not completely reliable for this purpose. We therefore used a macroarray dedicated to the 73 class III peroxidase genes of A. thaliana to identify genes potentially involved in flower and fruit development.

Results: The observed increase of total peroxidase activity during development was actually correlated with the induction of only a few class III peroxidase genes which supports the existence of a functional specialization of these proteins. We identified peroxidase genes that are predominantly expressed in one development stage and are probable components of the complex gene networks involved in the reproductive phase. An attempt has been made to gain insight into plausible functions of these genes by collecting and analyzing the expression data of different studies in plants. Peroxidase activity was additionally observed in situ in the silique dehiscence zone known to be involved in pod shattering. Because treatment with a peroxidase inhibitor delayed pod shattering, we subsequently studied mutants of transcription factors (TF) controlling this mechanism. Three peroxidases genes -AtPrx13, AtPrx30 and AtPrx55- were altered by the TFs involved in pod shatter.

Conclusions: Our data illustrated the problems caused by linking only an increase in total peroxidase activity to any specific development stage or function. The activity or involvement of specific class III peroxidase genes needs to be assessed. Several genes identified in our study had not been linked to any particular development stage or function until now. Notably AtPrx13, which is one of the peroxidase genes not present on commercially available microarrays. A systematic survey of class III peroxidase genes expression is necessary to reveal specific class III peroxidase gene functions and the regulation and evolution of this key multifunctional enzyme family. The approach used in this study highlights key individual genes that merit further investigation.
\end{abstract}

\section{Background}

Genes encoding secreted class III plant peroxidases (EC 1.11.1.7) are present in all land plants and form large multigenic families [1]. In their regular peroxidative cycle, class III peroxidases catalyze the reduction of

\footnotetext{
* Correspondence: Claudia.Cosio@unige.ch

'Institut Forel, University of Geneva, 10 route de Suisse, CP416, CH-1290 Versoix, Switzerland

Full list of author information is available at the end of the article
}

$\mathrm{H}_{2} \mathrm{O}_{2}$ by taking electrons to various donor molecules [2]. An hydroxylic cycle, which leads to the formation of various radical species such as $\mathrm{OH}$ or $\mathrm{HOO}$, has also been described [1]. Plant peroxidases are involved in a broad range of physiological processes throughout the plant life cycle [3], such as the formation of phenolic polymers as well as auxin catabolism [4-6]. The great number of plant peroxidases genes, the diversity of the processes catalyzed by them, as well as the presence of

\section{Ciomed Central}


both highly conserved domains and variable parts in all their sequences suggest the existence of a functional specialization of these proteins [7]. It is therefore imperative to link each individual gene with a precise role for a better understanding of the functions, the regulation and also the evolution of this key multifunctional enzyme family.

In an attempt to identify the function of specific class III peroxidases, several authors reported the generation of transgenic plants to study different peroxidase genes. However, in A. thaliana only 9 out of 73 peroxidase genes have been identified by this approach (Table 1). The characterisation of individual peroxidase mutants often gives only unconclusive results [8-12]. The in planta role of most peroxidases remains therefore elusive. This situation is mainly linked to two difficulties inherent in peroxidases: i) gene redundancy results in no visible mutant phenotype, and ii) the lack of substrate specificity in vitro, prohibits a determination of which compounds are real in planta substrate. Molecular biology approaches seems to offer a powerful tool to overcome these difficulties [7]. Transcriptome analysis for example provides a detailed description of the gene regulation during plant growth and development, in any plant tissue and also in different relevant genotypes. Thus a transcriptomic approach should permit an efficient screen showing which peroxidases are expressed at key developmental stages, but also to identify redundant peroxidases genes putatively involved in the same specific process in all kind of tissues, development stages and genotypes. Nevertheless, not all peroxidase genes are represented on commercially available microarrays. For this reason, in this study we used a home made macroarray dedicated exclusively to the 73 class III peroxidase genes of $A$. thaliana [13].

\begin{tabular}{|c|c|c|c|}
\hline $\begin{array}{l}\text { Protein } \\
\text { name }\end{array}$ & Organ & $\begin{array}{l}\text { Mechanism of interest of the } \\
\text { study }\end{array}$ & References \\
\hline AtPrx03 & roots & cold inducible tolerance & {$[57]$} \\
\hline AtPrx17 & flowers & silique lignification & [7] \\
\hline AtPrx21 & leaves & fungus defense & [59] \\
\hline \multirow[t]{2}{*}{ AtPrx33 } & leaves & oxidative burst & {$[35]$} \\
\hline & roots & root length & [74] \\
\hline \multirow[t]{2}{*}{ AtPrx34 } & leaves & oxidative burst & {$[35]$} \\
\hline & roots & root length & [74] \\
\hline AtPrx53 & $\begin{array}{l}\text { whole } \\
\text { plant }\end{array}$ & lignification of vascular bundles & {$[55]$} \\
\hline AtPrx62 & leaves & fungus defense & {$[59]$} \\
\hline AtPrx66 & roots & lignification of vascular bundles & [75] \\
\hline AtPrx71 & leaves & fungus defense & [59] \\
\hline
\end{tabular}

The aim of the present study was to identify class III peroxidase genes involved in flower and fruit development in A. thaliana. We conducted a macroarray analysis of the 73 class III peroxidase genes over 5 different development stages from flower buds to senescing siliques. These data were compared to class III peroxidase gene expression in leaves as well as combined with histological observations. Peroxidase activity was detected in situ in endocarp (en $b$ ) with heavy lignification associated with a simultaneous reduced cell-to-cell cohesion of the dehiscence zone (DZ) which is believed to be responsible for pod shattering $[14,15]$. In the present study, we further showed in A. thaliana that when class III peroxidase activity was inhibited pod shattering was delayed. We therefore analysed peroxidase gene expression in different plant lines known to be affected in pod shattering and identified three putative class III peroxidase genes whose expression was altered therein. Pod shatter is a well studied mechanism that is responsible for seed dispersal in Brassicacea including A. thaliana [16]. The vast majority of the genes identified to date in the process encode transcription factors involved in the regulation of gene expression. In contrast, comparatively few downstream target genes have been identified that are involved in organ formation. To our knowledge, no specific peroxidase gene has been shown to be involved in dry fruit maturation until now.

\section{Results}

Total peroxidase activity increases during development and senescence

Class III peroxidase activity was higher in roots than aerial parts and increased with the age of the plant (Figure $1 \mathrm{~A}$ ). After the $5^{\text {th }}$ week of growth, an increase of peroxidase activity coincided with bolting. In the aerial part, peroxidase activity also increased with the age of the organ (Figure 1B). Indeed, senescent leaves showed a 13-fold larger peroxidase activity than mature leaves and a 25 -fold higher activity than young leaves. In flowers and siliques, a similar evolution of the total peroxidase activity was observed. Senescent siliques (S2) showed a 2.4-fold higher activity than mature siliques (S1) and a 7.3-fold larger activity than senescing flowers (F3).

\section{Anthocyanin, chlorophyll and lignin content during development and senescence}

Chlorophyll loss, as well as anthocyanin and lignin increases, during development has been widely reported. These are known mechanisms associated with senescence and maturation that seem to be related with the increase in total peroxidase activity. In accordance with the literature, anthocyanin accumulation increased in senescing aerial organs (Figure 2A): senescing flowers 


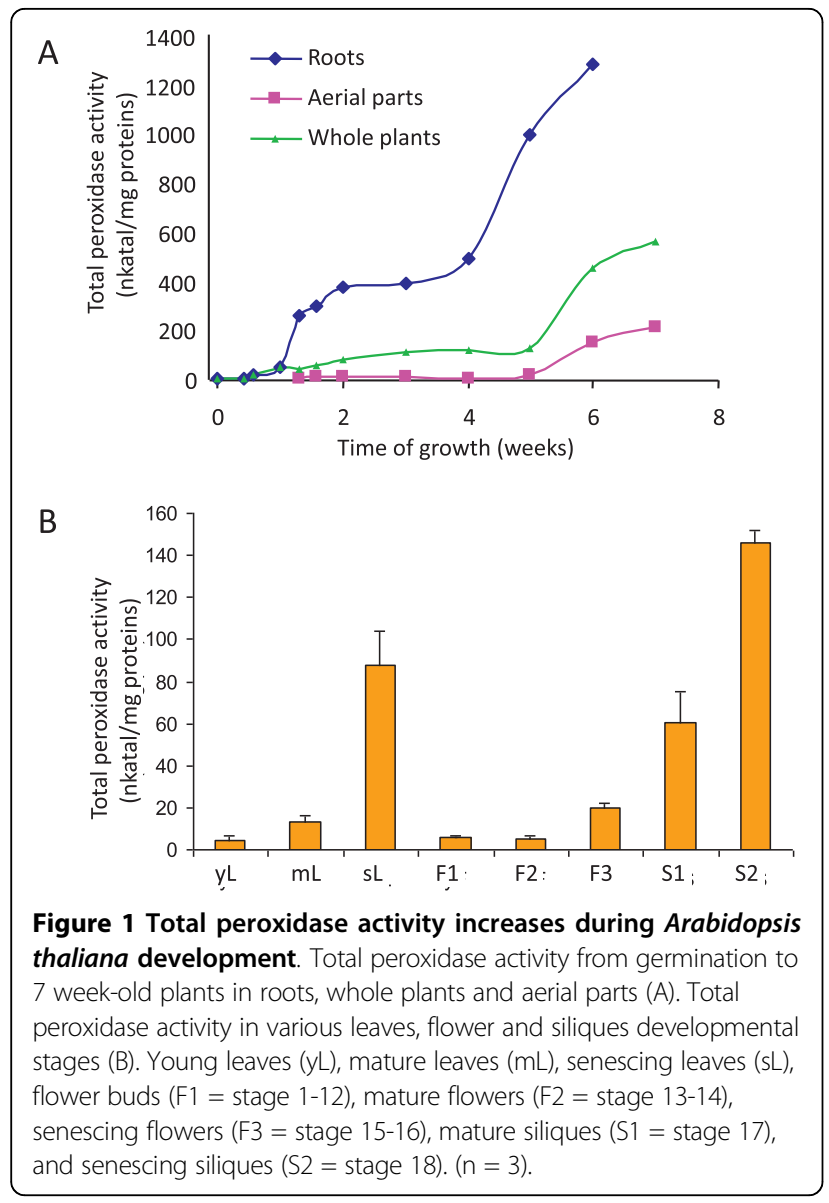

showed 4.4-fold larger anthocyanin content than buds, whereas senescing siliques contained 10.9-fold larger anthocyanin than mature siliques. Chlorophyll content decreased with the age of organs (Figure $2 \mathrm{~B}$ ): young leaves contained 1.8-fold and 3.9-fold more chlorophyll than mature leaves and senescing leaves respectively. In flowers and S1 siliques chlorophyll content was relatively stable showing no significant differences. In contrast, S1 siliques contained 3.1-fold more chlorophyll than senescing siliques. Lignin deposition increased over time in siliques but not in leaves or flowers (Figure 2C): in senescing siliques we monitored 1.4-fold and 2.3-fold larger lignin content than respectively in S1 siliques and senescing flowers.

It is probable that class III peroxidases have a role in the above developmental mechanisms, as widely admitted in the scientific community, but the link between these phenotypical observations and total peroxidase activity is rather indirect. We therefore wanted to assess changes in expression of class III peroxidases to indicate candidate genes for such processes. Gene expression data was then verified by observing peroxidase isoform pattern at the same developmental stages.

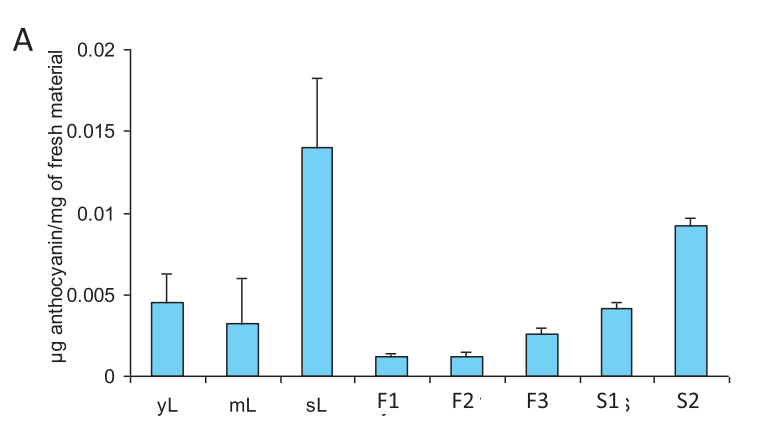

B
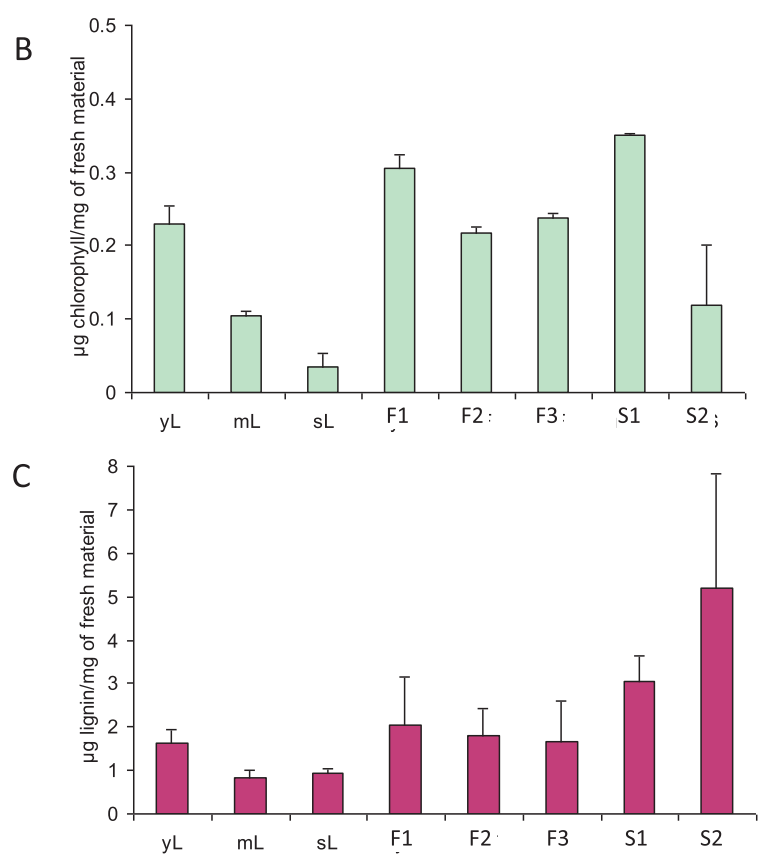

Figure 2 Chlorophyll (A), anthocyanin (B) and lignin (C) contents in various leaf, flower and silique development stages in Arabidopsis thaliana. Young leaves (yL), mature leaves $(\mathrm{mL})$, senescing leaves $(\mathrm{sL})$, flower buds $(\mathrm{F} 1)$, mature flowers $(F 2)$, senescing flowers (F3), mature siliques (S1), and senescing siliques (S2).

The increase of total peroxidase activity observed during development of flower and siliques is due to expression of only a few genes

The specific expression of the 73 peroxidase genes were observed using macroarrays in the various development stages of flowers and siliques (Figure 3A, Table 2, Table 3). Results were validated by semi-quantitative RT-PCR.

In fully opened flowers (F2) 42 genes were up-regulated, one was down-regulated and 30 genes had a relatively stable level of expression when compared to F1. In senescing flowers (F3) 10 genes were up-regulated, 23 genes down-regulated and 40 genes had relatively stable level of expression when compared to F1. In senescing siliques, only six genes were up-regulated, 52 genes were downregulated and 15 genes had relatively stable level of 


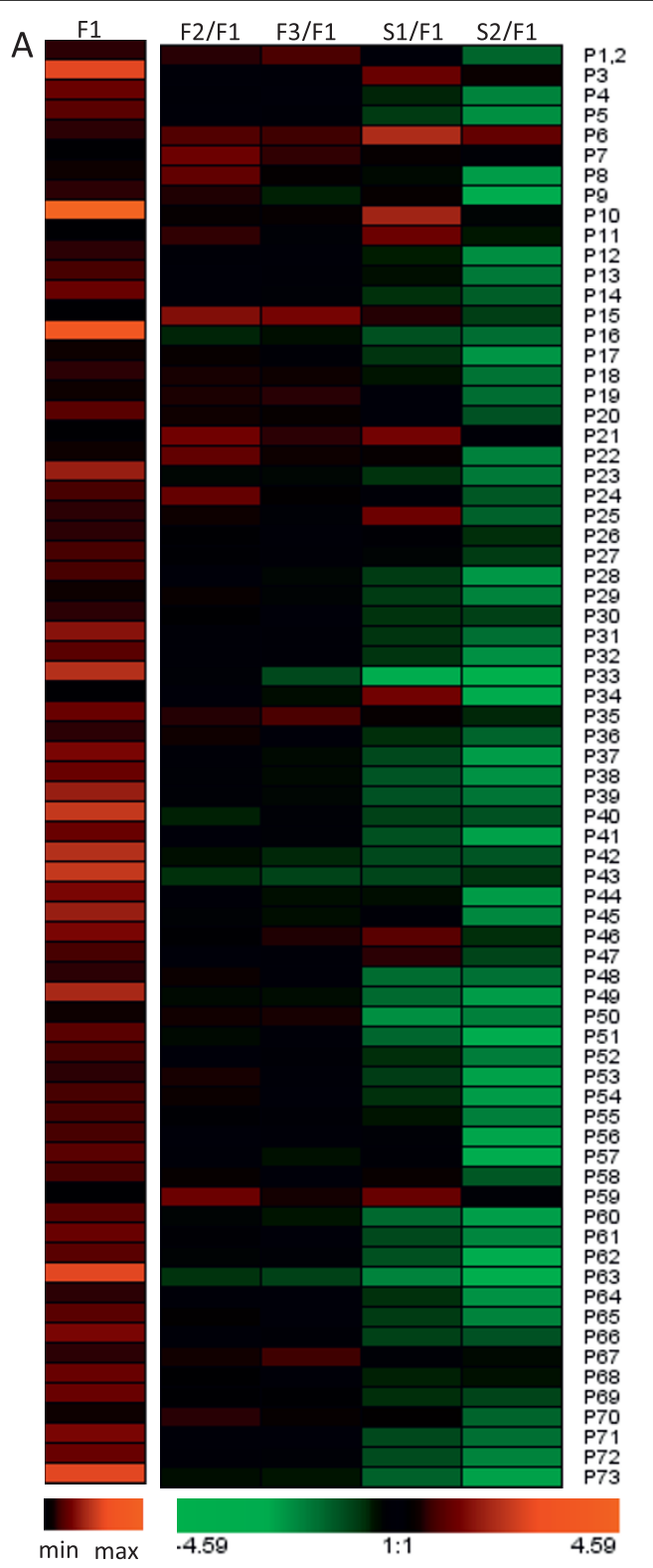

B

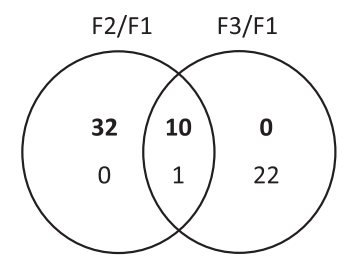

C

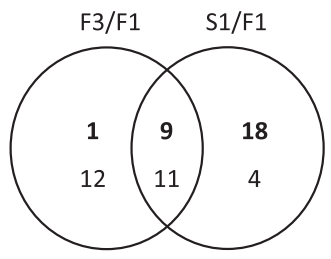

D

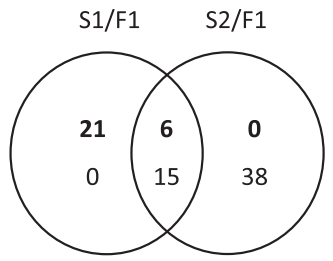

Figure 3 Peroxidase expression profile during flower and silique development at the gene level. (A). Macroarrays of flowers and siliques various stages (A). In the first column expression levels of each gene are represented as a ratio to the expression level of histone constitutively expressed gene $(n=3)$. In other columns, expression of peroxidase genes is represented as a ratio to their own expression level in F1 stage in log scale (A). Venn diagram illustrating the number of class III peroxidase genes up- (top and bold number) or down- (bottom number) regulated during various development stages when compared to F1 stage in A. thaliana (B-D) (F1 = stage 1-12, F2 = stage 13-14, F3 = stage 15$16, \mathrm{~S} 1=$ stage $17, \mathrm{~S} 2=$ stage 18 ). Only genes showing a differential expression of at least 1.3 up or 0.7 down and a significant Student t-test score $(p<0.05)$ were included in Venn diagrams (B-D).

expression when compared to F1. These data therefore indicated a general lower expression level of the vast majority of peroxidase genes in older development stages with the exception of stage S1. In the same line, the Venn diagram reveals that genes up-regulated in older stages were generally already up-regulated in earlier stages (Figure 3B-D). For example the 10 up-regulated genes in F3 or six genes up-regulated genes in S2 were already up- regulated in F2 and S1 respectively when compared to F1 (Figure 3B-D). Similarly, genes down-regulated in earlier stages are also generally down-regulated in older stages when compared to F1. These observations highlighted an expression coherence from the F1 to F3 and S1 to S2 stages. The only exception was again between the F3 and S1 stages where a new set of genes is apparently activated with 18 of the total 27 up-regulated genes not having been 
Table 2 Peroxidase genes the most highly and lowly expressed in the F1 stage in macroarray analysis as folddifference to the histone reference gene expression level

\begin{tabular}{lclc}
\hline gene & Expression level & gene & Expression level \\
\hline AtPrx10 & $2.37 \pm 0.01$ & AtPrx11 & $0.05 \pm 0.003$ \\
AtPrx16 & $1.94 \pm 0.004$ & AtPrx34 & $0.006 \pm 0.001$ \\
AtPrx03 & $1.38 \pm 0.053$ & AtPrx15 & $0.008 \pm 0.002$ \\
AtPrx73 & $1.35 \pm 0.049$ & AtPrx21 & $0.009 \pm 0.003$ \\
AtPrx63 & $1.41 \pm 0.014$ & AtPrx59 & $0.014 \pm 0.007$ \\
AtPrx40 & $1.19 \pm 0.06$ & AtPrx07 & $0.014 \pm 0.002$ \\
\hline
\end{tabular}

up-regulated in the F3 stage (Figure 3C). Amongst these S1 newly activated genes AtPrx03, AtPrx10, AtPrx11, AtPrx25, AtPrx34, AtPrx46 showed a fold-difference higher than 3.5 when compared to F1.

Macroarray analysis performed on 3 stages of leaves (young, mature and senescening; Figure 4) determined (4fold cut-off) that AtPrx04, AtPrx10, AtPrx24 and AtPrx42 have a significantly higher expression in flowers than leaves. On the contrary AtPrx11, AtPrx15, AtPrx21, AtPrx22, AtPrx37, AtPrx50, AtPrx51, AtPrx53, and AtPrx 59 are more expressed in leaves than flowers. The comparison also demonstrated the specific genes induced or repressed in leaves and flowers over time. For example, the expression of AtPrx59 or Atprx67 increased during development of flowers and siliques whereas they were relatively stable in leaves. On the contrary, AtPrx06, AtPrx07 were up-regulated, and AtPrx38, AtPrx41, AtPrx44, AtPrx73 were down-regulated in all organs.

\section{Peroxidase isoforms pattern at different developmental stages}

The pattern of the class III peroxidase isoforms at different flower and silique development stages was then analyzed by isoelectric focusing gel (IEF; Figure 5A). A maximum of 6 distinct bands were visible on the IEF in the different stages. Two basic bands (pI 8.3 and 9) were visible in all development stages although with great variation in intensity. These two bands showed the highest intensity in development stage F3. In development stage S2, the band of pI 8.3 was weaker than in younger stages and the band of $\mathrm{pI} 9$ showed a very low intensity. A band of pI 5.18 was only found in F1. Another band of pI 5.27 decreased from F1 to S1 and disappeared in S2. However, a band of pI 3.71 was induced in F2 and increased over time to S1. Another band of PI 8.74 was only induced in $\mathrm{S} 1$. Siliques S1 were further cut in four samples (Figure $5 \mathrm{~B})$ : the tip (the stigma and style), the ovary, the base (floral abscission zone), and the pedicel. The band of pI 8.74 was only detected in the ovary part (Figure $5 \mathrm{C}$ ). In conclusion, different specific isoforms were clearly induced or repressed from F1 to S2.

\section{Class III peroxidase activity is localized in specific tissues in siliques}

In order to see if we could link class III peroxidase activity with specific tissues we stained the flower and siliques for class III peroxidase activity. Activity was localized in the stigma, anthers, and floral abscission zone of flowers (Figure 6A). It was also observed in the stigma, floral abscission zone and on valve margin $\mathrm{DZ}$ of siliques (Figure 6B-D). Transversal cuttings of siliques presented peroxidase activity staining in the vascular bundles and also in the en $b$ (Figure 6E). Both tissues are highly lignified in siliques (Figure 6F).

Since class III peroxidase activity had been observed in the DZ and enb specialized cell layers (Figure 6) both known to be involved in pod shatter mechanism [17], we wanted to determine if class III peroxidase genes were involved in such a crucial mechanism.

\section{Treatment with a class III peroxidase inhibitor reduces} lignin content of siliques and results in pod shatter delay We first treated bolting plants with a class III peroxidase inhibitor salicylhydroxamate (SHAM) and monitored

Table 3 Expression level changes of peroxidase genes in macroarrays during flower and silique development

\begin{tabular}{|c|c|c|c|c|c|c|c|}
\hline $\begin{array}{c}\text { Highest in } \\
\text { F1 }\end{array}$ & $\begin{array}{c}\text { Highest in } \\
\text { F2 }\end{array}$ & $\begin{array}{c}\text { Highest in } \\
\text { S1 }\end{array}$ & $\begin{array}{l}\text { Highest in } \\
\text { F1-F2 }\end{array}$ & $\begin{array}{c}\text { Highest in } \\
\text { F1-F3 }\end{array}$ & $\begin{array}{l}\text { Highest in } \\
\text { S1-S2 }\end{array}$ & $\begin{array}{l}\text { Highest in } \\
\text { F2-S1 }\end{array}$ & $\begin{array}{c}\text { Stable } \\
\text { F1-S2 }\end{array}$ \\
\hline AtPrx16 & AtPrx7 & AtPrx 10 & AtPrx23 & AtPrx48 & AtPrx3 & AtPrx 1,2 & AtPrx 26 \\
\hline AtPrx43 & AtPrx8 & AtPrx 11 & AtPrx33 & AtPrx50 & AtPrx6 & AtPrx15 & AtPrx27 \\
\hline \multirow[t]{9}{*}{ AtPrx73 } & AtPrx24 & AtPrx25 & AtPrx37 & AtPrx51 & AtPrx7 & AtPrx20 & AtPrx30 \\
\hline & AtPrx29 & AtPrx34 & AtPrx38 & & & AtPrx21 & AtPrx36 \\
\hline & AtPrx36 & AtPrx45 & AtPrx41 & & & AtPrx22 & AtPrx40 \\
\hline & AtPrx48 & AtPrx46 & AtPrx45 & & & AtPrx35 & AtPrx42 \\
\hline & AtPrx53 & AtPrx47 & AtPrx49 & & & AtPrx59 & AtPrx43 \\
\hline & AtPrx55 & & AtPrx60 & & & & AtPrx66 \\
\hline & AtPrx58 & & AtPrx61 & & & & AtPrx68 \\
\hline & AtPrx65 & & AtPrx63 & & & & AtPrx>1 \\
\hline & AtPrx69 & & & & & & \\
\hline
\end{tabular}



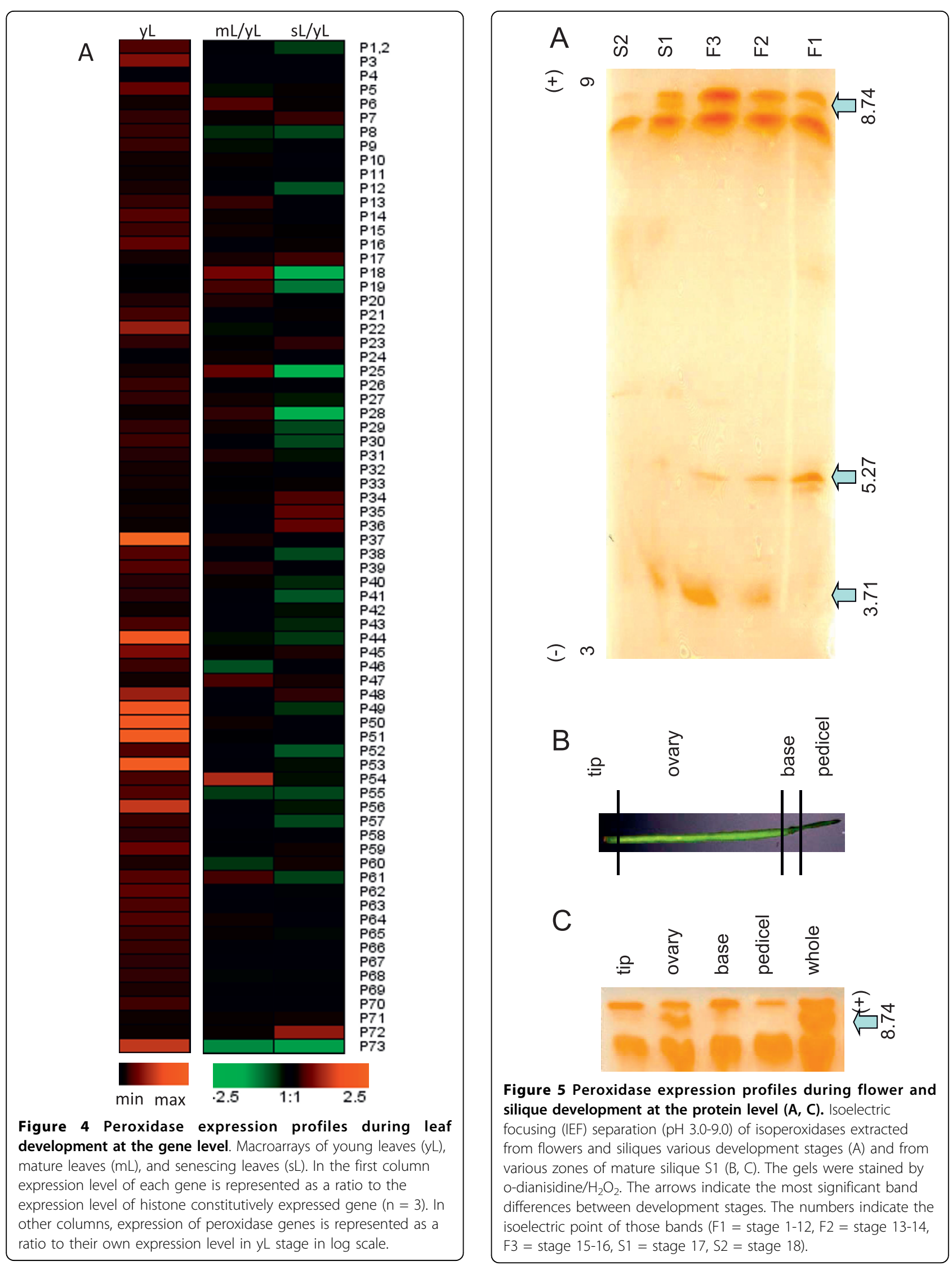


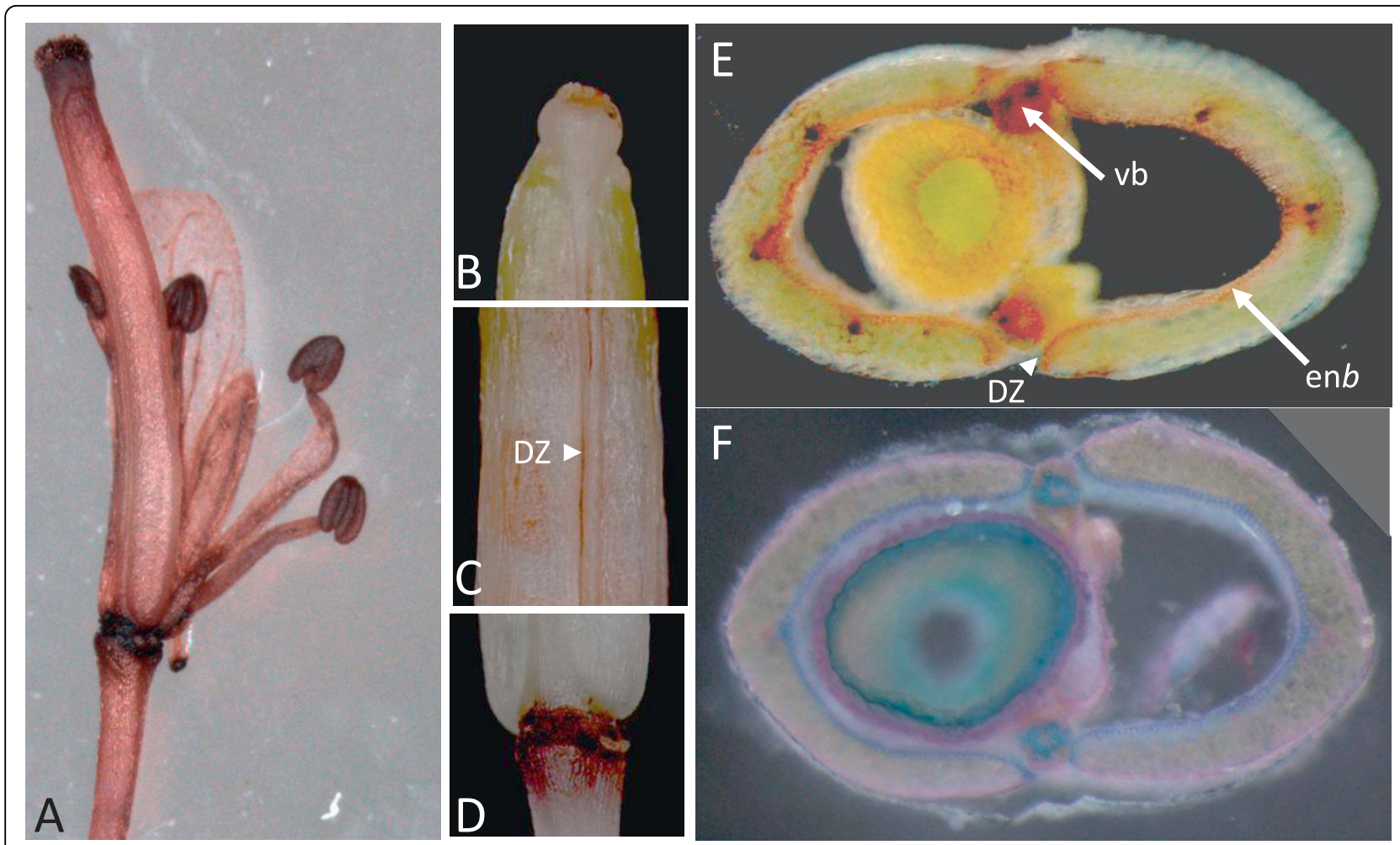

Figure 6 Flower (A) and mature silique (B-E) stained in situ by guaiacol/hydrogen peroxide for peroxidase activity and by carmino green for lignin accumulation (F). Silique tip (B), silique valves and replum showing staining in the dehiscence zone (C), floral abscission zone (D) and transversal cuttings showing staining of the endocarpb layer and vascular bundles $(E, F)$. DZ $=$ dehiscence zone, enb $=$ endocarp $b$, vb $=$ vascular bundle.

silique maturation. Treatment of plants with SHAM resulted in a delay in pod shatter, in the $1000 \mu \mathrm{M}$ and higher treatments (Figure 7A), and lowered total lignin content of siliques compared to non-treated plants (Figure 7B). A closer observation revealed that siliques opened easily when touched, indicating that hydrolysis of the DZ was unaffected but rather the spring-loaded mechanism was affected. Indeed it is thought that the lignification of the en $b$ layer creates tensions within the pod [14]. A lower total peroxidase activity (Figure 7C) due to the inhibitor treatment resulted in a less lignified silique that consequently does not shatter normally when drying.

\section{Several peroxidase genes are regulated by shatterproof and related transcription factors}

To identify specific peroxidase genes involved in pod shattering, we analyzed pod shatter mutant lines related to DZ lignification. Shatterproof transcription factors SHP1 and SHP2 are MADS-box transcription factors involved in dehiscence of the silique and control lignification of the siliques [17]. Because numerous peroxidase promoter regions contain a MADS-BOX binding sequence (data not shown), we chose to perform a transcriptomic study by macroarray analysis with shp 1 , $\operatorname{shp} 2$ and $\operatorname{shp} 1 \operatorname{shp} 2$ loss-of-function mutants, to identify class III peroxidase genes potentially regulated by shatterproof transcription factors. Macroarrays results (Figure $8 \mathrm{~A}$ ) were verified by semi-quantitative RT-PCR (Figure 8B). We focused on genes showing a significant altered expression in the three shatterproof mutant lines, that were in addition highly expressed in flowers/ siliques when compared to leaves (see above). Three genes of interest have been identified with these criteria: AtPrx $13(0.64 \pm 0.03,0.67 \pm 0.040 .69 \pm 0.04)$, AtPrx 30 $(0.38 \pm 3,0.32 \pm 0.03,0.50 \pm 0.09)$ that were significantly down-regulated, and AtPrx55 (2.78 $\pm 0.31,2.38 \pm$ $0.26,1.97 \pm 0.24)$ that was significantly up-regulated in $\operatorname{sh} 1, \operatorname{sh} p 2$ and $\operatorname{sh} p 1 \operatorname{sh} p 2$ respectively when compared to their respective expression level in Col 0 background.

To have a better idea of their regulation, we further monitored the expression of AtPrx13, AtPrx 30 and AtPrx 55 in a panel of other mutants of transcription factors involved in the regulation pod shatter (AG, FUL, RPL, IND and ALC; [16]) (Figure 8C-E). The results encompassing this study are schematized in the model presented in Figure 9 and are commented in the discussion section. 

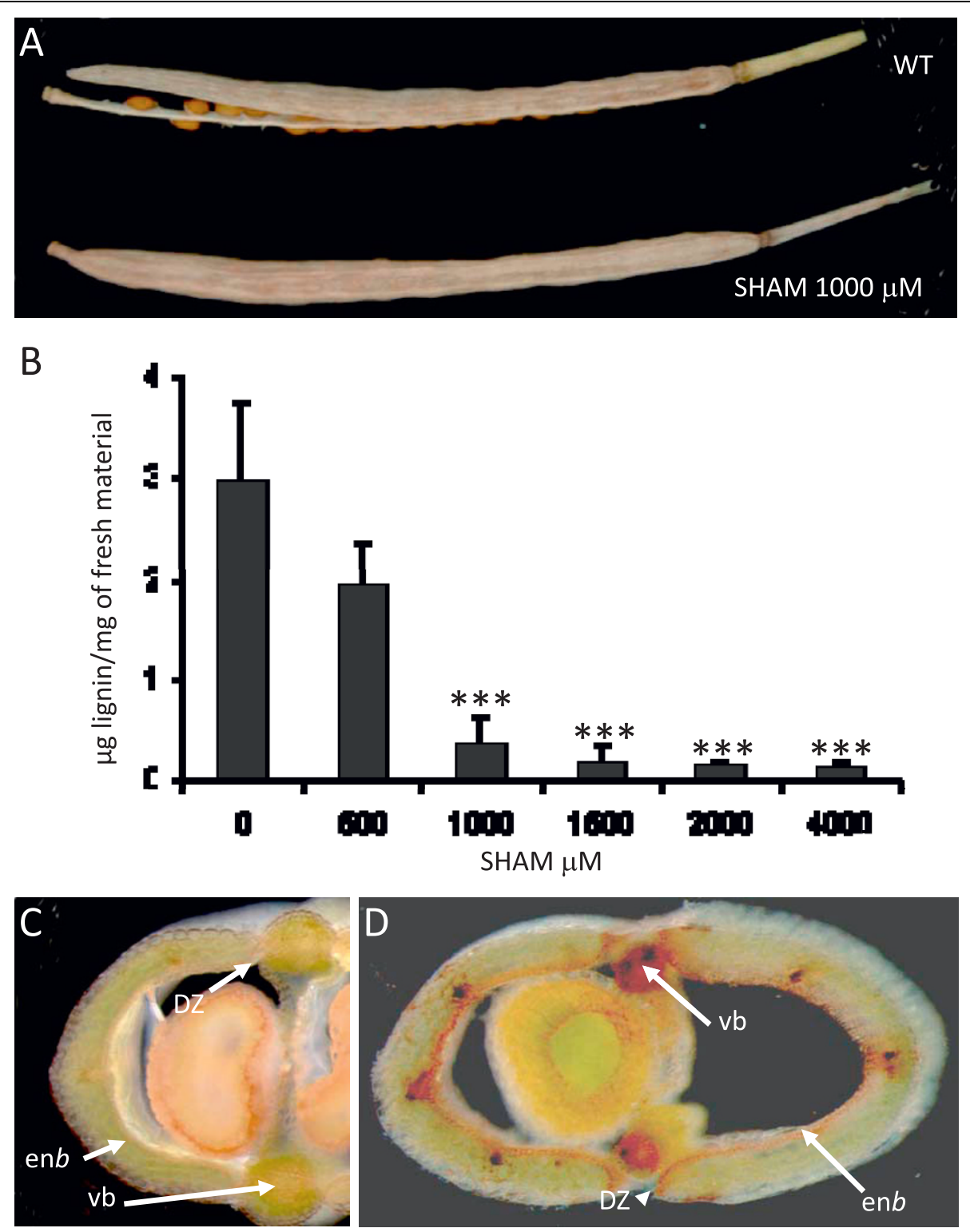

Figure 7 A peroxidase inhibitor-treatment (SHAM) resulted in a delay in pod shatter (A), a lower lignin content of siliques S2 (B), and lower peroxidase activity (C) when compared to WT (D). Total lignin content of siliques S2 in plants treated with various concentration of SHAM (Student $t$-test $p<0.001, n=6$ ) (B). Transversal sections of siliques of plants treated with $1000 \mu \mathrm{M}$ SHAM (C) and WT (D) stained in situ by guaiacol/hydrogen peroxide for peroxidase activity ( $D Z$ = dehiscence zone, enb = endocarp $b, \mathrm{vb}=$ vascular bundle).

In order to determine the putative in planta function of AtPrx13, AtPrx30 and AtPrx55, we ordered the respective SALK T-DNA insertion mutant lines. Unfortunately no reduction of the corresponding transcript was observed in these lines (data not shown). The TDNA was inserted in the promoter region for AtPrx 13 (SALK_100989) and AtPrx30 (Garlic_102_A09.b.1a. Lb3Fa), and not at the predicted position for AtPrx55 (SALK_102284; data not shown). We further monitored the expression of AtPrx13, AtPrx30 and AtPrx55 in various organ and development stages by semi-quantitative RT-PCR (Figure 8F). AtPrx13 and AtPrx55 were mainly expressed in silique stages. AtPrx30 was mainly expressed in flower stages. However the promoter regions of these three genes were assessed by PLACE (Table 4). Promoters of the three genes showed some similar regulatory sequences. For example GA-responsive elements, but also water-stress and light regulated elements (data not shown) were found in all of them. AtPrx 13 and AtPrx55 also contained a cis-sequence 


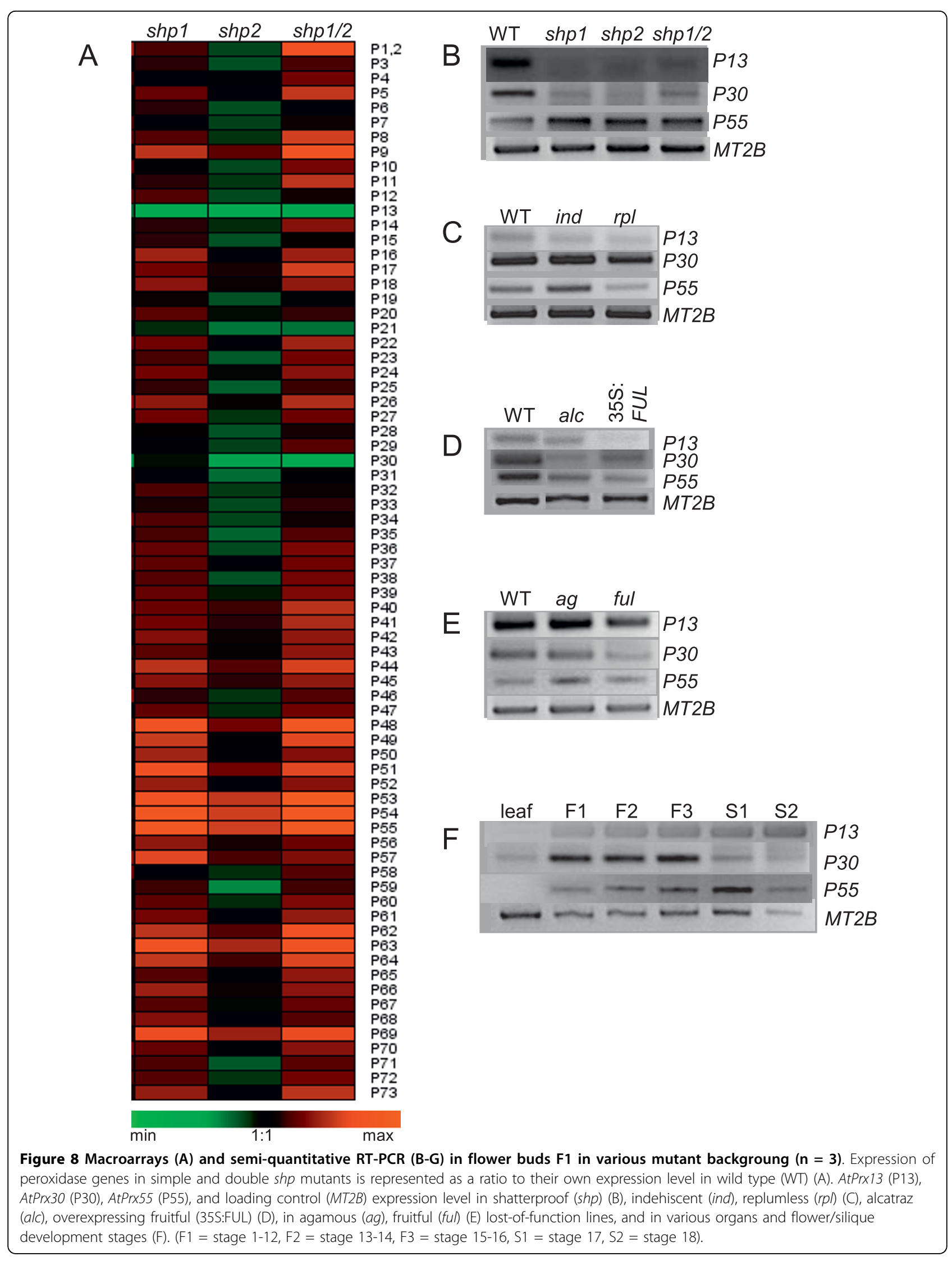


CARGAT found in promoter region of MADS-box flowering-time genes. In addition AtPrx30 and AtPrx55 showed an AGL2 (SEPALLATA1) binding sequence, whereas AtPrx30 showed a WUS binding site. It is interesting to note that AGL2 binding sequence was found in no other promoter region of class III peroxidase genes AtPrx 30 and AtPrx55. CARGAT and WUS binding sequence were found in only 6 and 18 of those respectively. Several other elements involved in phytohormone responsiveness were also found: abscisic acid (AtPrx13, AtPrx55), auxin (AtPrx13, AtPrx30), cytokinin (AtPrx30, AtPrx 55), ethylene (AtPrx13, AtPrx 55) and salicylic acid (AtPrx13). Nevertheless these last motifs are found in many of the promoter regions of other class III peroxidases. Therefore the possibility that the motif is found simply by chance increases. However, at this point the specific function and precise role of AtPrx 13, AtPrx 30 and AtPrx55 remains intriguing.

\section{Discussion}

The increase of total class III peroxidase activity is due to only a few specific peroxidases

Class III peroxidase activity increased during development and senescence in different tissues of several plant species [18-21]. Class III peroxidases are known to be involved in several events taking place during development and maturation such as chrorophyll degradation, anthocyanin accumulation or lignification [22-24]. In the present study in accordance with the literature [25-27], anthocyanin and lignin content increased whereas chlorophyll content decreased while total peroxidase activity increased. Nevertheless a plethora of other functions have been described and will be certainly further linked in the future to peroxidase activity [7]. However the specific genes involved in the general peroxidase activity increase as well as their specific function have not been identified yet in A. thaliana.
In this study, macroarrays allowed analysing temporal gene expression of the 73 class III peroxidase genes during flower and silique developments in A. thaliana. The expression profiles of peroxidase genes varied during flower and silique developments. Our data indicated a general lower gene expression level in the silique development stages but also an induction of different set of genes during the transition from flower to silique development. We identified a number of genes that are, within flowers, specifically or predominantly expressed in one development stage and are probable components of the gene networks involved in floral organ development. Indeed some of the events taking place in each of the development stages can be linked with peroxidase activity and localisation.

Class III peroxidases can regulate directly or indirectly the cell wall architecture through their catalytic and hydroxylic cycles. In growth stage F1, AtPrx 33 and AtPrx 43, already identified by a proteomic approach as having a role in cell elongation of hypocotyls [28], are highly expressed. At stage F2, the stigma is receptive, anthesis take place and fertilization occurs. Previously a stigma-specific class III peroxidase gene, SSP (stigmaspecific peroxidase) was identified which is expressed exclusively in the stigmas of an Asteraceae, Senecio squalidus L. $[29,30]$. Expression of SSP increases during flower development, to reach a maximum in newly opened flowers when stigmas are most receptive to pollen. So far its function is unknown but it may be related to regulation of $\mathrm{H}_{2} \mathrm{O}_{2}$ levels in stigmas. AtPrx58 appears in our study to have its highest level of expression in stage F2. In line with these data it has been identified as a stigma-specific gene and during pollen-pistil interaction by microarrays in two different studies [31,32]. In stage F3 sepals, petals and stamens wither and fall from the fruit. AtPrx51 that is highly expressed in this stage according to our study, has also been identified during

Table 4 Selected cis-regulatory element present in the 1000 bp upstream of the AtPrx13, AtPrx30, and AtPrx55 genes and their frequency in all 73 class III peroxidase gene promoters obtained with PLACE database

\begin{tabular}{|c|c|c|c|c|c|c|}
\hline \multirow[b]{2}{*}{ Motif } & \multirow[b]{2}{*}{ Sequence } & \multirow[b]{2}{*}{ Function } & \multicolumn{3}{|c|}{ Position in gene promoter } & \multirow[b]{2}{*}{ Frequency (\%) } \\
\hline & & & AtPrx13 & AtPrx30 & AtPrx55 & \\
\hline$\overline{\text { ABRE }}$ & MACGYGB & abscisic acid responsiveness & $251,510(-)$ & n.f. & 129 & 45 \\
\hline AGL2 & NNWNCCA[W] $]_{4} T_{R G}[W]_{2} A N$ & binding sequence of $A G L 2$ & 10 & n.f. & $383(-)$ & 3 \\
\hline ARFAT & TGTCTC & auxin response factor binding site & 319 & 936 & n.f. & 34 \\
\hline ASF1 & TGACG & activation of genes by auxin/salicylic acid & 543 & n.f. & n.f. & 45 \\
\hline CARGAT & $\mathrm{CC}[\mathrm{W}]_{6} \mathrm{GG}$ & found in MADS-box flowering-time gene & 14 & n.f. & 386 & 11 \\
\hline CPBCSPOR & TATTAG & cytokinin-enhanced protein binding in vitro & n.f. & $40,287(-), 647(-)$ & 518 & 68 \\
\hline ERELEE4 & AWTTCAAA & ethylene responsive element & $621(-)$ & n.f. & $414(-), 555(-)$ & 41 \\
\hline GARE & TAACAGA & gibberellin-responsive element & 773 & n.f. & n.f. & 11 \\
\hline GAHV & TAACAAA & gibberellin response complex & n.f. & 316 & $670(-), 814$ & 59 \\
\hline WUSTAG & TTAATGG & target sequence of WUS & n.f. & $917(-)$ & n.f. & 26 \\
\hline
\end{tabular}

Indicated positions are relative to the ATG codon $(M=A / C, W=A / T$, n.f. = not found). 
stamen abscission by microarrays [33]. However, the floral abscission zone is also strongly stained in situ for peroxidase activity and suberin (unpublished data). Cross-linking of the phenolic monomers in the formation of suberin has been linked with peroxidase activity [4]. Peroxidases could have a function in defense of the floral abscission zone against biotic attack, either through a cell wall cross-linking activity (formation of lignin, extensin cross-links, dityrosine bonds; [5]) or by creating a highly toxic environment by producing ROS $[34,35]$, which results in adverse growth conditions for microorganisms. A good candidate for such function could be AtPrx 50 for example. Indeed this gene is highly expressed during F3 stage in our study and has been identified during various studies concerning stresses $[36,37]$ as well as stamen abscission [33]. During stage $\mathrm{S} 1$, the fruit elongates to protect the seeds throughout their development. In addition, the valve margin and en $b$ layer lignified. Growth and lignification are functions classically attributed to class III peroxidases [22]. AtPrx02 has been shown to be involved in lignification, AtPrx 34 in root growth, and AtPrx45 in cell elongation $[28,38,39]$. At the end of fruit development at stage S2 the fruit yellows. Chlorophyll breakdown has been linked to peroxidase activity [23]. Nevertheless none of the genes expressed at this stage has been related yet to such a function.

To evaluate our data we compared our results with other published studies. Another study using the same macroarrays has been done earlier on inflorescences [13]. When comparing the two works, there was more convergence between highly expressed genes ( 8 out of 10) than lowly expressed genes (3 out of 10). A major difference was found for AtPrx 16 that is reported as lowly expressed in Valério et al. (2004) study and is amongst the most expressed genes in our study. Other authors performed whole genome microarray analysis on various flower stages [40-43]. Nevertheless, none of these studies has been performed on mature and senescent siliques limiting comparisons with our work. Four of the genes (AtPrx03, AtPrx40, AtPrx42, and AtPrx63) that we found as highly expressed in flower buds F1 were also found as highly expressed in at least one of the other microarray studies. Only one gene (AtPrx07) that we found as expressed at low amounts was also found as lowly expressed in one other study [40]. However, when comparing the 10 lowest and 10 highest expressed genes in flower buds only 2 and 7 genes coincided respectively between the two microarray analysis $[40,43]$. This clearly suggested that the highest expression levels are more reliably monitored than the lowest expression levels with these array techniques, including macroarrays and microarrays. Other techniques (e.g. RNA-seq) need to be used to study low-expressed genes. However it has to be noted that class III peroxidases have homologies ranging from $28 \%$ to $98 \%$ at the nucleotide level [13]. The advantage of our home-made macroarrays is that we used a set of primers exhibiting a maximum of only $70 \%$ homology with any other sequence of the $A$. thaliana genome [13]. Such an approach was of course not possible with whole genome microarrays such as those used by other authors [41-43], since they examined thousands of genes. It can therefore not be excluded that these authors detect an unspecific peroxidase genes expression level due to some level of cross-hybridation [13]. However, differences between our results and those of other scientists can be attributed to biological variation, growth conditions, experimental variations and use of different detection criteria. The use of a dedicated macroarray rather than a commercially available microarray also allowed analyzing data on genes not present on microarrays, such as AtPrx 13. However, although these array studies are of great value, they provide information that need to be confirmed.

We therefore continued the study at the protein level. On IEF a modification of the pattern of peroxidase isoforms between different development stages was also observed. In addition, different expression patterns were observed between the different parts of the S1 siliques: the band of pI 8.74 was only present in the ovary. Nevertheless, only six major bands were visible on the IEF, indicating that from the 73 peroxidase genes only the more active are visible and/or also that one bandparticularly the thicker ones-might be formed by several peroxidases of close pI. However, different specific isoforms were clearly induced or repressed in plant organs and probably as well in specific tissues and cell types over time. Our data indicated a general lower number of peroxidase isoforms in the silique S2 development stages. This result together with the macroarray analysis confirmed that the increase of total peroxidase activity observed with development in flower and siliques was due to only a few specific genes and not to an increase of the expression of all peroxidase genes. Senescence is known to be characterized by a progressive decrease of total protein content [44]. Probably reduced synthesis and enhanced proteolysis are both responsible for protein loss observed during senescence. In this regard, synthesis of all thylakoid proteins is known to be severely curtailed in senescing bean leaves except for the D1 protein of photosystem 2 [45]. The results presented in our study suggest that in the case of peroxidase a reduced synthesis might be predominant for the vast majority of the genes, therefore further supporting the existence of a functional specialization of peroxidases. 
Peroxidases are involved in pod shatter and probably other cell separation processes

Presence of peroxidase activity has been previously reported in stigma, anthers and AZ from different plants $[30,46,47]$, but to our knowledge it is the first time that peroxidases activity was localized in the en $b$ and DZ. However, a common feature of several of these areas where peroxidases have been observed is their involvement in some kind of cell separation process including pod shatter, anthers dehiscence, and floral organ abscission [48-50].

To further identify the genes potentially expressed in en $b$ and DZ, we analyzed class III peroxidase gene expression profiles in mutants related to pod-shattering and compared to their expression in WT. AtPrx13 and $A t \operatorname{Pr} x 30$ were significantly down-regulated, on the contrary AtPrx55 was significantly up-regulated in the three loss-of-function shp mutant lines, suggesting that these three genes are expressed in en $b$. The three genes were mainly expressed in flower or siliques. In addition, several regulatory sequences identified in the promoter regions of these three genes further supported their role in flower development. The expression of AtPrx13, Atprx30 and AtPrx55 were also monitored in a panel of other loss-of-function mutants related to en $b$ development (ag, ful, rpl, ind and alc). FUL, IND, ALC, SHP1/2 appear to be expressed together in the en $b$ layer, although the nature of the interaction of these antagonistic factors is unclear and their precise role in en $b$ development has remained elusive $[16,17]$. However the loss of enb lignification is only seen in the ful ind alc shp1 shp2 quintuple mutant, indicating that all genes are involved in en $b$ lignification. In our model (Figure 9) it can be observed that AtPrx55 expression level is affected in all these mutant lines, indicating a good

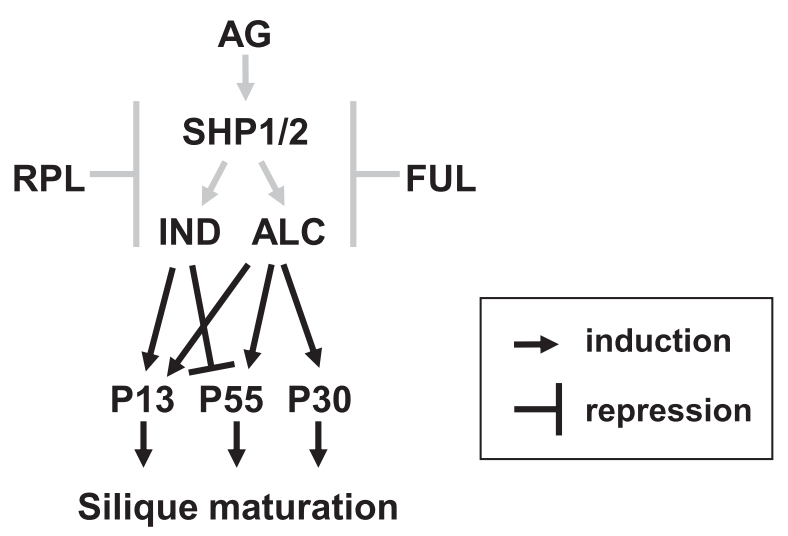

Figure 9 Model of the observed interactions between the three identified peroxidases genes and the transcription factors known to be involved in pod shatter mechanism. Interactions represented in grey are based on the literature. candidate for lignification of siliques except that the gene was down-regulated by SHP1 and SHP2. Indeed, we would expect the opposite regulation for a gene involved in lignification of en $b$. However, class III peroxidases can generate highly reactive ROS which can possess an intrinsic activity, or can act as part of signal transduction pathways [51,52]. Maybe AtPrx55 is one of the peroxidases with such activity. Unfortunately, AtPrx55 is not documented in the literature preventing further hypothesis on its putative function. AtPrx30 on the other hand is up regulated by the SHP transcription factors and has also been identified by microarrays in stamen AZ and in monolignol polymerization suggesting its putative involvement in both silique DZ as well as stamen AZ lignification [33,38]. All cell separation process involves the differentiation of specialized cell types and a tight co-ordination of molecular and biochemical events [53]. There is accumulating evidences that common mechanisms exist between the different cell separation process $[48,49,54]$. For instance RDPG1, an endopolygalacturonase involved in cell wall breakdown during silique opening of oilseed rape (Brassica napus), has been found also in dehiscence zones of anthers and floral abscission zones and stylar tissues during pollen tube growth in Arabidopsis and Brassica [48]. Moreover transcription factors (ALC, AG) known to be involved in regulation of pod shattering have also been identified in a microarray study concerning stamen $\mathrm{AZ}$ [33]. In addition, several peroxidase genes (AtPrx03, AtPrx17, AtPrx21, AtPrx31, AtPrx33, AtPrx34, AtPrx42, AtPrx45, AtPrx50, AtPrx51, AtPrx52, AtPrx53, AtPrx67, AtPrx71) have been identified in the study concerning stamen AZ, illustrating the redundancy of this protein family and the complexity in assigning a function to a class III peroxidase genes. Six of these genes (AtPrx21, AtPrx31, AtPrx33, AtPrx34, AtPrx53, AtPrx71) were identified in our study on $s h p$ loss-of-function mutants, further supporting the existence of common mechanisms in the various cell separation processes. Several of these genes have also been reported in studies concerning responses to abiotic or biotic stresses (AtPrx03, AtPrx21, AtPrx33, AtPrx34, AtPrx45, AtPrx50, AtPrx52, AtPrx67, AtPrx71) or lignin synthesis (AtPrx17, AtPrx53) giving some additional indication on their putative role [7,35-38,55-61]. AtPrx 13 on the opposite is not documented in the literature and in the microarray databases. However, the precise role of each peroxidase gene in cell separation processes needs to be elucidated.

In $A$. thaliana, the DZ and the en $b$ are composed by highly specialized cells essentially involved in the pod shatter mechanism. A lignification of the en $b$ layer happens at stage 17 of silique development, and is necessary for a proper shatter mechanism $[14,16]$. A well known function of class III peroxidases is lignification 
[22]. In our study, the observation of peroxidase activity in these specialized tissues further supported a possible involvement through lignification of various peroxidase genes in cell separation processes and particularly in the pod shattering mechanism. In the present study we showed that plants treated with peroxidase inhibitor produced siliques with lower lignin content resulting in a delay of pod shattering. A good spatio-temporal correlation was found between abscission zone weakening and increased peroxidase activity in Phaseolus, cherry fruit, cotton, and Citrus [47,62-65]. Nevertheless several mechanisms that can be related to peroxidase activity have been observed in the abscission zone. Expression data associated with the leaf abscission in Citrus indicated the occurrence of a double defensive strategy mediated by the activation of a biochemical program including ROS scavenging, defense and PR genes, and a physical response mostly based on lignin/suberin deposition [65]. ROS scavenging, defense and lignin deposition are linked to peroxidases and may be related to the considerable increase in peroxidase activity $[47,66]$. Lignin has been proposed to have a double role as a physical barrier of the protective layer developed on the part of the organ that remains attached to the plant and also as component of the fracture line favoring cell separation [65]. On the other hand class III peroxidases can also produce ROS $[34,35]$, which results in adverse growth conditions for microorganisms. During cell separation processes, peroxidase expression could also be triggered as a preventive defense mechanism against pathogen attacks [67].

\section{Conclusions}

Our data illustrate the difficulty in interpreting total peroxidase activity data when trying to link it to specific functions. During flower and siliques development total peroxidase activity increased sharply, but the level of expression of most genes and the number of bands visible on IEF stayed stable or even decreased. This study confirms the necessity to study peroxidases individually to comprehend the roles of the class III peroxidase family. Indeed, many functions have been attributed to class III peroxidases [3], however the majority of individual peroxidase genes function still needs to be assessed [7]. The approach used in this study - to identify class III peroxidase genes changes specific to flower and silique maturation in A. thaliana by transcriptome analysis-highlights which are the key individual genes to investigate further by reverse genetics approaches. Whole transcriptome analysis is indeed the most promising approach for overcoming the difficulties associated with the study of class III peroxidase function. The dedicated macroarray used here proved to be a cheap and efficient tool for this aim.

\section{Methods}

\section{Plant material and growth conditions}

Arabidopsis thaliana plants were grown at $24^{\circ} \mathrm{C}$ under $16 \mathrm{~h}$ light $/ 8 \mathrm{~h}$ dark and $60 \%$ humidity and with $80 \mu$ Einstein $\mathrm{m}^{-2} \mathrm{~s}^{-1}$ of light intensity first 7 days on $1 / 2$ MS medium [68] and then transferred to soil. Organs such as flower buds (F1 = stage 1-12, see [16]), mature flowers (F2 = stage 13-14), senescing flowers (F3 = stage 15-16), mature siliques $(\mathrm{S} 1=$ stage 17$)$, senescing siliques $(\mathrm{S} 2=$ stage 18 ), young leaves ( $\mathrm{yL}=$ small leaves on top of rosette), mature leaves ( $\mathrm{mL}=$ full expanded leaves) and senescing leaves ( $\mathrm{sL}=$ partly yellowing leaves) used for total RNA and protein extractions were collected and immediately frozen in liquid nitrogen.

Ecotypes and mutants of Arabidopsis used were Col 0 (WT), Ler (WT), shp1-1, shp2-2, shp1-1 and shp2-2, AtPrx13 (SALK_100989), AtPrx30 (Garlic_102_A09.b.1a. Lb3Fa), AtPrx55 (SALK_102284) in Col background (obtained from the European Arabidopsis Stock Centre [NASC], University of Nottingham, United Kingdom), ful, ag Ler, (NASC), alc-1, rpl-2, ind-2, 35S:FUL (Col, gift from Lars Østergaard, John Innes Centre, Norwich, UK).

\section{Chlorophyll content}

Fresh material was incubated overnight in the dark in 1 $\mathrm{ml} 80 \%$ acetone. Absorbance of the supernatant was measured at $663 \mathrm{~nm}$ and $647 \mathrm{~nm}$ and converted to $\mu \mathrm{g}$ of chlorophyll using the following formula:

$$
\left(\mathrm{DO}_{663 \mathrm{~nm}} * 7.15\right)+\left(\mathrm{DO}_{647 \mathrm{~nm}} * 18.71\right) \text {. }
$$

\section{Anthocyanin content}

Fresh material was ground in $300 \mu \mathrm{l} 1 \%$ methanol- $\mathrm{HCl}$ and incubated overnight at room temperature. $200 \mu \mathrm{l}$ water and $500 \mu \mathrm{l}$ chloroform were added, and the insoluble residues were eliminated by centrifugation. The absorbance was measured at $530 \mathrm{~nm}$ and $657 \mathrm{~nm}$ and converted to $\mu \mathrm{g}$ of anthocyanin using the following formula:

$$
\mathrm{DO}_{530 \mathrm{~nm}}-\left(\mathrm{DO}_{657 \mathrm{~nm}} * 0.25\right) \text {. }
$$

\section{Lignin content}

Thioglycolic acid extraction of lignin was performed as described elsewhere [69] with some modifications. Fresh material was resuspended twice in $1 \mathrm{ml}$ ethanol. After centrifugation at $10000 \mathrm{~g}$, the pellets were dried at $60^{\circ} \mathrm{C}$. The insoluble cell wall material (about $20 \mathrm{mg}$ ) was resuspended in $500 \mu \mathrm{l} 2 \mathrm{~N} \mathrm{HCl}$ and $50 \mu \mathrm{l}$ thioglycolic acid (Fluka). The mixture was heated for $4 \mathrm{~h}$ in boiling water and centrifuged at $10000 \mathrm{~g}$ for $15 \mathrm{~min}$. After washing with water, the pellets were resuspended in 500 $\mu \mathrm{l} 0.5 \mathrm{~N} \mathrm{NaOH}$ and left $18 \mathrm{~h}$ shaking softly at room temperature. The insoluble residues were eliminated by centrifugation and lignin thioglycolate was precipitated 
by the addition of $100 \mu \mathrm{l}$ concentrated $\mathrm{HCl}\left(4 \mathrm{~h}\right.$ at $\left.4^{\circ} \mathrm{C}\right)$. After centrifugation at $10000 \mathrm{~g}$ for $15 \mathrm{~min}$, the pellets were resuspended in $1 \mathrm{ml} 0.5 \mathrm{~N} \mathrm{NaOH}$. The absorbance was measured at $280 \mathrm{~nm}$ and converted to $\mu \mathrm{g}$ lignin using lignin alkali (Aldrich) as a standard.

\section{Macroarray experiments}

Total RNA was isolated from flowers or leaves with Trireagent solution (Sigma) and from siliques according to a protocol described elsewhere [70] with the addition of a sodium acetate wash to remove excess polysaccharides. Messenger RNA for the cDNA probe synthesis was obtained from $500 \mu \mathrm{g}$ total RNA with the PolyAtract mRNA Isolation System kit (Promega). The cDNA was labeled by incorporating $50 \mu \mathrm{Ci}$ of [alpha- ${ }^{32} \mathrm{P}$ ]dATP during reverse transcription using random primers, according to the ImPromII RT (Promega) protocol.

PCR products (90-400 bp) corresponding to the 73 peroxidases genes and two pseudogenes were used for the macroarray approach. The specificity of amplicons is related to their low homology (less than 70\% against the whole Arabidopsis genome) and has already been verified experimentally [13]. $50 \mathrm{ng}$ of each amplicon were blotted on a nylon membrane and hybridized in triplicates with the radiolabeled cDNA library as described previously [13]. The constitutively expressed A. thaliana putative histone H4 (At2 g28740) was used as positive control to normalize the expression data and the peroxidase pseudogene I was utilized as a negative control. Genesis software was use to graphically present the ratio of expression level in log scale [71]. Only genes showing a differential expression of at least 1.3 up or 0.7 down and a significant Student $\mathrm{t}$-test score $(\mathrm{p}<0.05)$ were included in Venn diagrams.

\section{Relative-quantitative Reverse Transcriptase PCR}

Reverse Transcriptase-PCR (RT-PCR) was used as a semi-quantitative method to assess the expression of peroxidase genes. Flowers or siliques were harvested and frozen immediately in liquid nitrogen. $100 \mathrm{mg}$ of tissue sample were ground in liquid nitrogen, and total RNA was extracted with the Tri-reagent solution (Sigma) according to the instructions of the manufacturer. After quantification of the concentration by spectrophotometry and confirmation by electrophoresis, $1 \mu \mathrm{g}$ of the crude RNA preparations was treated with one unit of RNase-free DNase I (Promega). The DNA-free RNA was then used as a template during reverse transcription according to the ImPromII RT protocol from Promega. PCR amplification was conducted for up to 35 cycles using the following thermal profile: denaturation at $95^{\circ} \mathrm{C}$ for $1 \mathrm{~min}$, annealing at $55^{\circ} \mathrm{C}$ for $1 \mathrm{~min}$, and polymerization at $72^{\circ} \mathrm{C}$ for $30 \mathrm{~s}$, with a $10 \mathrm{~min}$ terminal extension step at $72^{\circ} \mathrm{C}$. Primers used for peroxidases genes were the same as for the macroarray experiments [13]. Reactions without RT were used as control to rule out contamination by genomic DNA. To determine whether comparable amounts of RNA from the different tissues had been used for RT-PCR, the level of metallothionein gene, $M T 2 B$ (5'-ACATGTCTTGCTGTGGTGGA-3' and 5'-ATGACCAAACCATAAAAAC ACAC-3') was used as an internal standard [72]. Densitometric analysis of ethidium bromide-stained agarose gels (1\%) was then performed. The relative abundance of the transcript within the samples was calculated as the ratio of the intensities of the gene amplicon to the $M T 2 B$ amplicon. Reactions were performed in triplicate and averaged.

\section{Separation of class III peroxidase isoforms}

Soluble proteins were extracted from the various organs by grinding in $20 \mathrm{mM}$ Hepes, $\mathrm{pH}$ 7.0, containing $1 \mathrm{mM}$ EGTA, $10 \mathrm{mM}$ vitamin C, and PVP PolyclarAT (100 $\mathrm{mg} / \mathrm{g}$ fresh weight). The extract was centrifuged twice for $10 \mathrm{~min}$ at $10000 \mathrm{~g}$. Each extract was assayed for proteins levels with Bio-Rad assay (Bio-Rad) and for total class III peroxidase activity using guaïacol/ $/ \mathrm{H}_{2} \mathrm{O}_{2}$.

Gel isoelectric focusing (IEF) was performed with Servalyt precotes gels $\mathrm{pH}$ 3-10 (Serva) according to the instruction of the manufacturer. $10 \mu \mathrm{g}$ of total proteins were loaded per line. Class III peroxidase activity was revealed with o-dianisidine $/ \mathrm{H}_{2} \mathrm{O}_{2}$.

\section{Organs staining}

After $12 \mathrm{~h}$ of bleaching with 100\% EtOH to remove chlorophyll, flowers and siliques were stained for class III peroxidase activity using guaiacol/ $/ \mathrm{H}_{2} \mathrm{O}_{2}$ resulting in an orange to brown coloration. Lignin localization was performed with green carmino that colours lignified tissues in green and cellulose in pink. Organs were incubated 10 min in the different preparations. Reactions were stopped by transferring the organs in distilled water.

Except when specified, observations were made with a MZ 16 Leica stereomicroscope (Leica Mycrosystems $\mathrm{GmbH}$ ). Pictures were taken with a DC300F Leica camera. Settings were identical for all the pictures in an experiment. Each kind of experiment was repeated at least 4 times with similar results.

\section{Salicylhydroxamate (SHAM) treatment}

Arabidopsis thaliana seeds were germinated on $1 / 2 \mathrm{MS}$ medium. Four one-week-old seedlings were transferred to a $1000 \mathrm{~mL}$ pots filled with modified one-quarterstrength Hoagland nutrient solution (Sigma) supplemented with $20 \mu \mathrm{M}$ Fe-HBED (Strem Chemical). 500 to $4000 \mu \mathrm{M}$ SHAM - a class III peroxidase inhibitor [73]was added in nutrient solution just after bolting. Three pots per treatment were set up. The nutrient solution was renewed every week and aerated continuously. 


\section{Acknowledgements}

We are grateful to Professor Claude Penel, now retired, for his financial and scientific support. We thank Lars Østergaard for kindly giving us some of the seeds used in this study. We would like to thank Dr William Deakin (University of Geneva, Switzerland) for critical reading of the manuscript and Rebeka Doyle and Neil Graham for their manuscript editing to improve the English. CC and CD were supported by the Swiss National Science Foundation (grant 31-068003.02). CC was in addition supported by a grant from the Schmidheiny Foundation.

\section{Author details}

'Institut Forel, University of Geneva, 10 route de Suisse, CP416, CH-1290 Versoix, Switzerland. ${ }^{2}$ SCSV-UMR5546 CNRS/UPS, 24 Chemin de Borderouge, BP 42617, 31326 Castanet-Tolosan, France.

\section{Authors' contributions}

CC designed, performed and wrote up the work. CD developed the class ॥ specific macroarrays, participated in the design and coordination of the study and helped to draft the manuscript. Both authors read and approved the final manuscript

Received: 12 April 2010 Accepted: 29 September 2010

Published: 29 September 2010

\section{References}

1. Passardi F, Penel C, Dunand C: Performing the paradoxical: how plant peroxidases modify the cell wall. Trends Plant Sci 2004, 9(11):534-540.

2. Hiraga S, Sasaki K, Ito H, Ohashi Y, Matsui H: A large family of class III plant peroxidases. Plant Cell Physiol 2001, 42(5):462-468.

3. Passardi F, Cosio C, Penel C, Dunand C: Peroxidases have more functions than a Swiss army knife. Plant Cell Rep 2005, 24(5):255-265.

4. Bernards MA, Summerhurst DK, Razem FA: Oxidases, peroxidases and hydrogen peroxide: the suberin connection. Phytochemistry Reviews 2004, 3:113-126.

5. Chen EL, Chen YA, Chen LM, Liu ZH: Effect of copper on peroxidase activity and lignin content in Raphanus sativus. Plant Physiology and Biochemistry 2002, 40(5):439-444.

6. Cosio C, Zheng Y, Perry S, Dunand C: Peroxidase involved in pod shatter mechanisms. XVI Congress of the Federation of European Societies of Plant Biology (FEBSP): 2008 Tampere, Finland 2008, P10-019

7. Cosio C, Dunand C: Specific functions of individual class III peroxidases genes. Journal of Experimental Botany 2009, 60:391-408.

8. Sherf BA, Bajar AM, Kolattukudy PE: Abolition of an inducible highly anionic peroxidase-activity in transgenic tomato. Plant Physiology 1993, 101(1):201-208.

9. McIntyre $\mathrm{CL}$, Bettenay HM, Manners JM: Strategies for the suppression of peroxidase gene expression in tobacco. 2. In vivo suppression of peroxidase activity in transgenic tobacco using ribozyme and antisense constructs. Transgenic Res 1996, 5(4):263-270.

10. Kristensen BK, Brandt J, Bojsen $\mathrm{K}$, ThordalChristensen $\mathrm{H}$, Kerby KB, Collinge DB, Mikkelsen JD, Rasmussen SK: Expression of a defence-related intercellular barley peroxidase in transgenic tobacco. Plant Science 1997, 122(2):173-182.

11. Ray H, Douches DS, Hammerschmidt R: Transformation of potato with cucumber peroxidase: expression and disease response. Physiol Mol Plant Pathol 1998, 53(2):93-103.

12. Schlimme M, Blaschke L, Lagrimini LM, Polle A: Growth performance and lignification in tobacco with suppressed apoplastic anionic peroxidase activity under ambient and elevated $\mathrm{CO}_{2}$ concentrations. Int J Plant Sci 2002, 163(5):749-754

13. Valério L, De Meyer M, Penel C, Dunand C: Expression analysis of the Arabidopsis peroxidase multigenic family. Phytochemistry 2004 65(10):1331-1342.

14. Spence J, Vercher Y, Gates P, Harris N: 'Pod shatter' in Arabidopsis thaliana, Brassica napus and B-juncea. J Microsc-Oxf 1996, 181:195-203.

15. Meakin PJ, Roberts JA: Dehiscence of fruit in oilseed rape (Brassica napus L.).2. the role of cell-wall degrading enzymes and ethylene. Journal of Experimental Botany 1990, 41(229):1003-1011.

16. Roeder AHK, Yanofsky MF: Fruit development in Arabidopsis. In The Arabidopsis book. Edited by: Somerville SC, EM M. Rockville: American Society of Plant Biologist; 2006:
17. Liljegren SJ, Roeder AHK, Kempin SA, Gremski K, Ostergaard L, Guimil S, Reyes DK, Yanofsky MF: Control of fruit patterning in Arabidopsis by INDEHISCENT. Cell 2004, 116(6):843-853.

18. Pearse IS, Heath KD, Cheeseman JM: Biochemical and ecological characterization of two peroxidase isoenzymes from the mangrove, Rhizophora mangle. Plant Cell and Environment 2005, 28(5):612-622.

19. Qin TT, Fu JF, Zhang NH, Du LF: Comparative studies of senescencerelated enzymes in the cotyledon of chlorophyll b-deficient mutant and its wild type oilseed rape during senescence. Plant Science 2006, 171(3):293-299.

20. Chakrabarty D, Chatterjee J, Datta SK: Oxidative stress and antioxidant activity as the basis of senescence in chrysanthemum florets. Plant Growth Regulation 2007, 53(2):107-115.

21. Stolle-Smits T, Beekhuizen JG, Kok MTC, Pijnenburg M, Recourt K, Derksen J, Voragen AGJ: Changes in cell wall polysaccharides of green bean pods during development. Plant Physiology 1999, 121(2):363-372.

22. Barcelo AR, Ros LVG, Carrasco AE: Looking for syringyl peroxidases. Trends in plant science 2007, 12(11):486-491.

23. Kunieda T, Amano T, Shioi Y: Search for chlorophyll degradation enzyme, Mg-dechelatase, from extracts of Chenopodium album with native and artificial substrates. Plant Science 2005, 169(1):177-183.

24. Zhou S, Sauve RJ, Howard EF: Identification of a cellwall peroxidase in red calli of prunus incisa Thund. Plant Cell Rep 2002, 21:380-384.

25. Hortensteiner S: Stay-green regulates chlorophyll and chlorophyll-binding protein degradation during senescence. Trends in plant science 2009, 14(3):155-162.

26. Nooden LD, Hillsberg JW, Schneider MJ: Induction of leaf senescence in Arabidopsis thaliana by long days through a light-dosage effect. Physiologia Plantarum 1996, 96(3):491-495.

27. Tallis MJ, Lin Y, Rogers A, Zhang J, Street NR, Miglietta F, Karnosky DF, De Angelis P, Calfapietra C, Taylor G: The transcriptome of Populus in elevated $\mathrm{CO} 2$ reveals increased anthocyanin biosynthesis during delayed autumnal senescence. New Phytologist 2010, 186(2):415-428.

28. Irshad $\mathrm{M}$, Canut $H$, Borderies $G$, Pont-Lezica $R$, Jamet E: A new picture of cell wall protein dynamics in elongating cells of Arabidopsis thaliana: confirmed actors and newcomers. BMC Plant Biology 2008, 8:94.

29. McInnis SM, Costa LM, Gutierrez-Marcos JF, Henderson CA, Hiscock SJ: Isolation and characterization of a polymorphic stigma-specific class III peroxidase gene from Senecio squalidus L. (Asteraceae). Plant Mol Biol 2005, 57(5):659-677.

30. McInnis SM, Desikan R, Hancock JT, Hiscock SJ: Production of reactive oxygen species and reactive nitrogen species by angiosperm stigmas and pollen: potential signalling crosstalk? New Phytologist 2006, 172(2):221-228.

31. Swanson $R$, Clark T, Preuss D: Expression profiling of Arabidopsis stigma tissue identifies stigma-specific genes. Sexual Plant Reproduction 2005, 18(4):163-171.

32. Tung CW, Dwyer KG, Nasrallah ME, Nasrallah JB: Genome-wide identification of genes expressed in Arabidopsis pistils specifically along the path of pollen tube growth. Plant Physiology 2005, 138(2):977-989.

33. Cai S, Lashbrook CC: Stamen abscission zone transcriptome profiling reveals new candidates for abscission control: enhanced retention of floral organs in transgenic plants overexpressing Arabidopsis ZINC FINGER PROTEIN2. Plant Physiology 2008, 146(3):1305-1321.

34. Delannoy E, Jalloul A, Assigbetse K, Marmey P, Giger JP, Lherminier J, Daniel JF, Martinez C, Nicole M: Activity of class III peroxidases in the defense of cotton to bacterial blight. Molecular Plant-Microbe interactions 2003, 16(11):1030-1038.

35. Bindschedler LV, Dewdney J, Blee KA, Stone JM, Asai T, Plotnikov J, Denoux C, Hayes T, Gerrish C, Davies DR, et al: Peroxidase-dependent apoplastic oxidative burst in Arabidopsis required for pathogen resistance. Plant Journal 2006, 47(6):851-863.

36. Klok EJ, Wilson IW, Wilson D, Chapman SC, Ewing RM, Somerville SC, Peacock WJ, Dolferus R, Dennis ES: Expression profile analysis of the lowoxygen response in Arabidopsis root cultures. Plant Cell 2002, 14(10):2481-2494.

37. Hammond JP, Bennett MJ, Bowen HC, Broadley MR, Eastwood DC, May ST, Rahn C, Swarup R, Woolaway KE, White PJ: Changes in gene expression in Arabidopsis shoots during phosphate starvation and the potential for developing smart plants. Plant Physiology 2003, 132(2):578-596. 
38. Ehlting J, Mattheus N, Aeschliman DS, Li EY, Hamberger B, Cullis IF, Zhuang J, Kaneda M, Mansfield SD, Samuels L, et al: Global transcript profiling of primary stems from Arabidopsis thaliana identifies candidate genes for missing links in lignin biosynthesis and transcriptional regulators of fiber differentiation. Plant Journal 2005, 42(5):618-640.

39. Passardi F, Tognolli M, De Meyer M, Penel C, Dunand C: Two cell wall associated peroxidases from Arabidopsis influence root elongation. Planta 2006, 223(5):965-974.

40. Zhang XH, Feng BM, Zhang Q, Zhang DY, Altman N, Ma H: Genome-wide expression profiling and identification of gene activities during early flower development in Arabidopsis. Plant molecular biology 2005, 58(3):401-419.

41. Hennig L, Gruissem W, Grossniklaus U, Kohler C: Transcriptional programs of early reproductive stages in Arabidopsis. Plant Physiology 2004, 135(3):1765-1775.

42. Wellmer F, Riechmann JL, Alves-Ferreira M, Meyerowitz EM: Genome-wide analysis of spatial gene expression in Arabidopsis flowers. Plant cell 2004, 16(5):1314-1326

43. Wellmer F, Alves-Ferreira M, Dubois A, Riechmann JL, Meyerowitz EM: Genome-wide analysis of gene expression during early Arabidopsis flower development. PLoS Genet 2006, 2(7):1012-1024.

44. Prochazkova D, Wilhelmova N: Leaf senescence and activities of the antioxidant enzymes. Biologia plantarum 2007, 51(3):401-406.

45. Droillard MJ, Bate NJ, Rothstein SJ, Thompson JE: Active translation of the D-1 protein of photosystem-II in senescing leaves. Plant Physiology 1992, 99(2):589-594.

46. Sawhney VK, Nave EB: Enzymatic changes in postmoeiotic anther development in petunia-hybrida.2. Histochemical-localization of esterase, peroxidase, malate-dehiydrogenase and alcoholdehydrogenase. Journal of Plant Physiology 1986, 125(5):467-473.

47. McManus MT: Peroxidases in the separation zone during ethyleneinduced bean leaf abscission. Phytochemistry 1994, 35(3):567-572.

48. Sander L, Child R, Ulvskov P, Albrechtsen M, Borkhardt B: Analysis of a dehiscence zone endo-polygalacturonase in oilseed rape (Brassica napus) and Arabidopsis thaliana: evidence for roles in cell separation in dehiscence and abscission zones, and in stylar tissues during pollen tube growth. Plant molecular biology 2001, 46(4):469-479.

49. Roberts JA, Elliott KA, Gonzalez-Carranza ZH: Abscission, dehiscence, and other cell separation processes. Annu Rev Plant Biol 2002, 53:131-158

50. Suen DF, Wu SSH, Chang HC, Dhugga KS, Huang AHC: Cell wall reactive proteins in the coat and wall of maize pollen - Potential role in pollen tube growth on the stigma and through the style. Journal of Biological Chemistry 2003, 278(44):43672-43681.

51. Passardi F, Longet D, Penel C, Dunand C: The class III peroxidase multigenic family in rice and its evolution in land plants. Phytochemistry 2004, 65(13):1879-1893.

52. Laloi $C$, Apel K, Danon A: Reactive oxygen signalling: the latest news. Current Opinion in plant biology 2004, 7(3):323-328.

53. Patterson SE: Cutting loose. Abscission and dehiscence in Arabidopsis. Plant Physiology 2001, 126(2):494-500.

54. Stenvik GE, Butenko MA, Urbanowicz BR, Rose JKC, Aalen RB: Overexpression of INFLORESCENCE DEFICIENT IN ABSCISSION activates cell separation in vestigial abscission zones in Arabidopsis. Plant cell 2006, 18(6):1467-1476

55. Ostergaard L, Teilum K, Mirza O, Mattsson O, Petersen M, Welinder KG, Mundy J, Gajhede M, Henriksen A: Arabidopsis ATP A2 peroxidase. Expression and high-resolution structure of a plant peroxidase with implications for lignification. Plant Mol Biol 2000, 44(2):231-243.

56. Cheong YH, Chang HS, Gupta R, Wang X, Zhu T, Luan S: Transcriptional profiling reveals novel interactions between wounding, pathogen, abiotic stress, and hormonal responses in Arabidopsis. Plant Physiology 2002, 129(2):661-677

57. Llorente F, Lopez-Cobollo RM, Catala R, Martinez-Zapater JM, Salinas J: A novel cold-inducible gene from Arabidopsis, $\mathrm{RCI} 3$, encodes a peroxidase that constitutes a component for stress tolerance. Plant Journal 2002, 32(1):13-24.

58. Yokoyama R, Nishitani K: Identification and characterization of Arabidopsis thaliana genes involved in xylem secondary cell walls. Journal of Plant Research 2006, 119(3):189-194.

59. Chassot C, Nawrath C, Metraux JP: Cuticular defects lead to full immunity to a major plant pathogen. Plant Journal 2007, 49(6):972-980.
60. Mohr PG, Cahill DM: Suppression by ABA of salicylic acid and lignin accumulation and the expression of multiple genes, in Arabidopsis infected with Pseudomonas syringae pv. tomato. Functional \& Integrative Genomics 2007, 7(3):181-191.

61. Kumari M, Taylor GJ, Deyholos MK: Transcriptomic responses to aluminum stress in roots of Arabidopsis thaliana. Mol Genet Genomics 2008, 279(4):339-357.

62. Henry EW, Valdovin Jg, Jensen TE: Peroxidases in tobacco abscission zone tissues.2. time course studies of peroxidases-activity during ethyleneinduced abscission. Plant Physiology 1974, 54(2):192-196.

63. Wittenbach VA, Bukovac MJ: Cherry fruit abscission - peroxidase-activity in abscission zone in relation to separation. J Am Soc Hortic Sci 1975, 100(4):387-391.

64. Morgan PW, Fowler JL: Ethylene: Modification of peroxidase activity and isozyme complement in cotton (Gossypium hirsutum L.). Plant Cell Physiol 1972, 13(4):727-736.

65. Agusti J, Merelo P, Cercos M, Tadeo FR, Talon M: Ethylene-induced differential gene expression during abscission of citrus leaves. Journal of Experimental Botany 2008, 59(10):2717-2733.

66. vanDoorn WG, Stead AD: Abscission of flowers and floral parts. J Exp Bot 1997, 48(309):821-837.

67. El Mansouri I, Mercado JA, Santiago-Domenech N, Pliego-Alfaro F, Valpuesta V, Quesada MA: Biochemical and phenotypical characterization of transgenic tomato plants overexpressing a basic peroxidase. Physiologia Plantarum 1999, 106(4):355-362.

68. Murashige T, Skoog F: A revised medium for rapid growth and bio-assay with tobacco tissue culture. Physiol Plant 1962, 15:473-497.

69. Bruce RJ, West CA: Elicitation of lignin biosynthesis and isoperoxidase activity by pectic fragments in suspension-cultures of castor bean. Plant Physiology 1989, 91(3):889-897.

70. Downing WL, Mauxion F, Fauvarque MO, Reviron MP, Devienne D, Vartanian N, Giraudat J: A Brassica-napus transcript encoding a protein related to the kunitz protease inhibitor family accumulates upon waterstress in leaves, not in seeds. Plant Journal 1992, 2(5):685-693.

71. Sturn A, Quackenbush J, Trajanoski Z: Genesis: cluster analysis of microarray data. Bioinformatics 2002, 18(1):207-208.

72. Zhou J, Goldsbrough PB: Structure, organization and expression of methallothionein gene family in Arabidopsis. Mol Gen Genet 1995, 248:318-328.

73. Simonovicova M, Huttova J, Mistrik I, Siroka B, Tamas L: Peroxidase mediated hydrogen peroxide production in barley roots grown under stress conditions. Plant Growth Regulation 2004, 44(3):267-275.

74. Passardi F, Dobias J, Valerio L, Guimil S, Penel C, Dunand C: Morphological and physiological traits of three major Arabidopsis thaliana accessions. J Plant Physiol 2006

75. Sato Y, Demura T, Yamawaki K, Inoue Y, Sato S, Sugiyama M, Fukuda H: Isolation and characterization of a novel peroxidase gene ZPO-C whose expression and function are closely associated with lignification during tracheary element differentiation. Plant Cell Physiol 2006, 47(4):493-503.

doi:10.1186/1471-2164-11-528

Cite this article as: Cosio and Dunand: Transcriptome analysis of various flower and silique development stages indicates a set of class III peroxidase genes potentially involved in pod shattering in Arabidopsis thaliana. BMC Genomics 2010 11:528.

\section{Submit your next manuscript to BioMed Central and take full advantage of:}

- Convenient online submission

- Thorough peer review

- No space constraints or color figure charges

- Immediate publication on acceptance

- Inclusion in PubMed, CAS, Scopus and Google Scholar

- Research which is freely available for redistribution 